\title{
Revisiting Splenectomy in Childhood Immune Thrombocytopenic Purpura in the Era of New Therapies: The French Experience
}

Nathalie Aladjidi ${ }^{1,2 *}$, Raoul Santiago ${ }^{1,2}$, Corinne Pondarré ${ }^{3}$, Anne Lambilliotte ${ }^{4}$, Guy Leverger ${ }^{5}$, Claire Godard Sebillotte ${ }^{6}$, Vincent Barlogis ${ }^{7}$, Pierre Rohrlich ${ }^{8}$, Marlène Pasquet ${ }^{9}$, Sophie Bayart ${ }^{10}$, Dominique Plantaz ${ }^{11}$, Patrick Lutz ${ }^{12}$, Karine de Bosredon ${ }^{13}$, Aude Marie-Cardine ${ }^{14}$, Corinne Guitton ${ }^{15}$, Patrick Boutard ${ }^{16}$, Martine Munzer ${ }^{17}$, Jean-Louis Stephan ${ }^{18}$, Thierry Leblanc ${ }^{19}$ and Y. Perel ${ }^{1,2}$

${ }^{1} \mathrm{CHU}$ Bordeaux, Centre de Référence National des Cytopénies Auto-immunes de l'Enfant(CEREVANCE), Place Amélie Raba Léon, 33 076 Bordeaux, France

${ }^{2}$ Pediatric Hematologic Unit, University Hospital, Place Amélie Raba Léon, 33076 Bordeaux, France

${ }^{3}$ Pediatric Hematologic Unit, University Hospital - IHOP, Lyon, 69008 Bordeaux, France

${ }^{4}$ Pediatric Hematologic Unit, University Hospital, 59037 Lille, France

${ }^{5}$ Pediatric Hematologic Unit, University Hospital - Trousseau - APHP, 75012 Paris, France

6INSERM/UPMC UMR-S 707, 75007 Paris, France

${ }^{7}$ Pediatric Hematologic Unit, University Hospital - APHM, 13385 Marseille, France

${ }^{8}$ Pediatric Hematologic Unit, University Hospital, 25030 Besançon, France

${ }^{9}$ Pediatric Hematologic Unit, University Hospital, 31026 Toulouse, France

${ }^{10}$ Pediatric Hematologic Unit, University Hospital, 35203 Rennes, France

${ }^{11}$ Pediatric Hematologic Unit, University Hospital, 38043 Grenoble, France

${ }^{12}$ Pediatric Hematologic Unit, University Hospital, 67098 Strasbourg, France

${ }^{13}$ Department of Nuclear Medicine, University Hospital, Place Amélie Raba Léon, 33076 Bordeaux, France

${ }^{14}$ Pediatric Hematologic Unit, University Hospital, 76031 Rouen, France

${ }^{15}$ Pediatric Hematologic Unit, University Hospital, 94275 Le Kremelin Bicêtre, France

${ }^{16}$ Pediatric Hematologic Unit, University Hospital, 14033 Caen, France

${ }^{17}$ Pediatric Hematologic Unit, University Hospital, 51092 Reims, France

${ }^{18}$ Pediatric Hematologic Unit, University Hospital, 42055 Saint-Etienne, France

${ }^{19}$ Pediatric Hematologic Unit, University Hospital - Robert Debré - APHP, 75019 Paris, France

\begin{abstract}
Objective: While splenectomy is the gold standard treatment for refractory primary immune thrombocytopenia (ITP) in adult, its place remains debated in children. The French Rare Disease Plan provided us the opportunity to conduct a collaborative study of the efficiency and tolerance of this procedure in childhood ITP.

Patients and methods: A retrospective study was conducted in France in order to identify children with ITP treated with splenectomy during a 9-year period. A total of 78 children were included. Data from the ongoing CEREVANCE national cohort of childhood auto-immune cytopenia in 30 units were reviewed and completed by a direct contact with the referent physicians. International terminology for response definition was used. Relapsefree survival was assessed by the Kaplan-Meier method.

Results: The median ages at ITP diagnosis and splenectomy were 9.6 and 12.4 years respectively. The median duration of ITP before splenectomy was 24 months (1-162); 62 children had chronic ITP. The median number of treatment lines before splenectomy was 2 (1-7). Laparoscopy was used in $81 \%$ of cases. Four children underwent immediate surgical complications. With a median follow-up of 41 months, complete remission (CR) was maintained at the latest news in $84 \%$ of children. CR was obtained in $77 \%$ of cases with intra-splenic platelets destruction, and in no case with non-splenic destruction $(p=0.11)$. Using a very strict definition for relapse, the 5-year relapse-free survival was 51\% [IC95\% 37-64]. No death or overwhelming sepsis was reported.

Conclusions: In this national study with a long term follow up, the excellent benefit/risk ratio of splenectomy for refractory ITP confirms that in skilled and concerted teams, the procedure is still at the forefront of curative treatments. Isotopic evaluation is of value but other prognostic factors for CR are to be determined. Lifelong survey of potential infectious and thrombotic risk at adult age has to be coordinated by the referring physician. The place for other therapeutic options, in order to postpone as late as possible the splenectomy in childhood ITP is now to be determined.
\end{abstract}

Keywords: Children; ITP; Autoimmune cytopenia

Abbreviations: CEREVANCE: National Reference Center for Auto-Immune Cytopenia in Children; CR: Complete Remission; CCR: Continuous and Complete Remission; ITP: Immune Thrombocytopenic Purpura; IVIg: Intra-Venous Immunoglobulin; M1: One month post splenectomy; NR: Non Remission; OPSI: Overwhelming Postsplenectomy Infections; PR: Partial Remission; SHIP: Society of Pediatric Hematology and Immunology

\section{Introduction}

Immune thrombocytopenia (ITP) is one of the rare causes of childhood thrombocytopenia, defined as peripheral isolated thrombocytopenia under $100 \mathrm{G} / \mathrm{L}$. The incidence of newly diagnosed ITP is 2.2 to $5.3 / 10^{5}$ children/year [1]. In children, ITP is usually an acute self-limiting disease. In contrast with adult patients, a chronic course of more than 12 months only occurs in $20 \%$ of cases and only a small percentage of these cases may require second-lines therapies 
[2-7]. Treatment issues are to limit the bleeding risk, which may be life-threatening, and to maintain a good quality of life [8-10]. There are no evidence-based guidelines available for the treatment of chronic ITP in children. Treatment decisions and recommendations are mainly based on expert opinions [11-14]. As the spleen is the organ primarily responsible for the destruction of antibody-sensitized platelets, splenectomy remains the most reliable therapeutic option in adult ITP, allowing long-term remission in approximately $60-70 \%$ of cases [15]. The place of splenectomy in childhood ITP is still debated, because of the unpredictable occurrence of spontaneous recovery, the paucity of purely pediatric comparative data, and the risk of Overwhelming PostSplenectomy Infections (OPSI). At a time when many new therapeutic options are available with various potential side effects, it seems essential to share our standard pediatric practices, and to elaborate more precise guidelines highlighting the benefit/risk balance of each option.

CEREVANCE is a national pediatric group devoted to childhood autoimmune cytopenias, which is active from 2001 on behalf of the French Society of Hematology and Immunology (SHIP), officially recognized in 2007 with the Rare Diseases Plan of the French Health Ministry. A national prospective cohort of children with auto-immune cytopenia was started in 2004, and from 2008 also includes chronic ITP [16]. The aim of the present work was to retrospectively describe children who underwent a splenectomy for ITP, and to analyze the efficiency and tolerance of this procedure.

\section{Design and Methods}

\section{Selection of patients}

In our country, children with chronic ITP are systematically referred by primary pediatric centers to pediatric hematologist when the indication of second-line therapies has to be discussed.

In September 1, 2009 the 30 French pediatric hematological units were requested to report the children and adolescents living in France, who had undergone a splenectomy for ITP between January 1, 2000 and August 31, 2009. Children were identified by previous registration in the CEREVANCE national prospective cohort of childhood chronic ITP constituted from 2008 ( $\mathrm{n}=275)$, crossed with the medicoeconomic information system used in French hospitals and the surgical databases in most of the centers. The research was approved by institutional review boards according to local requirements, and informed parental consent was obtained.

\section{Inclusion and exclusion criteria}

Inclusion criteria were a diagnosis of ITP according to the 2009 International Working Group (IWG) criteria (peripheral isolated thrombocytopenia less than $100 \mathrm{G} / \mathrm{L}$ ) and age less than 18 years at splenectomy. IWG criteria were retrospectively used to define newlydiagnosed, persistent and chronic ITP. In order to diagnose secondary ITP, extensive clinical and biological screening for Evans syndrome, auto-immune lymphoproliferative syndrome, common variable immune deficiency, lupus or other auto-immune disease was conducted annually from initial diagnosis to last follow up. Patients who, at any point in the following period, presented any criteria of secondary ITP were excluded [17].

\section{Collection of data and medical procedures}

Detailed data were checked from each patient's medical record by an independent single reader, and the treating physicians were contacted by phone at the time of the study to update the latest news, concerning efficiency and tolerance. All issues were collected on an individual specific file. Relevant clinical, biological and therapeutic data, from initial diagnosis of ITP to last follow-up, were recorded. Specific therapeutic management before and after splenectomy, surgical procedures and anti-infection measures were described. Diagnosis and therapeutic procedures were left to the physician appreciation, when locally available ${ }^{111}$ Indium-labeled autologous platelet scanning was performed in order to study platelet lifespan and the site of platelet destruction [18].

\section{Definitions}

The bleeding severity at diagnosis was evaluated by the Buchanan score [19], and the presence of mucous or visceral significant bleeding was recorded. "On-demand treatments" were defined as treatments used to temporarily increase the platelet count in case of major bleeding, infection or trauma (Intravenous Immunoglobulin (IVIg) or short courses of steroids). Specific treatments were all immunomodulatory or immunosuppressive treatments. Patients followed for less than one month after splenectomy were considered as lost to follow-up. The response to splenectomy was determined by the hemorrhagic score and the platelet count at scheduled intervals after splenectomy: immediate response at the first month (M1), then every year until last followup. As recommended by the IWG, response criteria were as follows: Complete Response (CR): platelet count more than $100 \mathrm{G} / \mathrm{L}$ and absence of bleeding; Partial Response (PR): platelet count more than $30 \mathrm{G} / \mathrm{L}$ and at least a twofold increase in the baseline count and absence of bleeding; No Response (NR): platelet count less than $30 \mathrm{G} / \mathrm{L}$ or less than a twofold increase in the baseline count or bleeding [17]. A relapse was defined by the loss of complete response, even if it was transient, or the need of demand or specific treatment. Considering the frequency of oscillating platelet count during the course of chronic ITP, even after apparent remission, the CEREVANCE group aimed at identifying a long lasting sustained response subgroup: Continuous Complete Remission (CCR) was defined as a sustained CR at the last follow up allowed by splenectomy, with no further relapse and no additional on-demand or specific therapy.

\section{Statistical analysis}

Qualitative data were analyzed with the Fisher exact test. The significant limit for $\mathrm{p}$ values was $\mathrm{p} \leq 0.05$. Relapse-free survival was described by the Kaplan-Meier method. The time interval was defined from the splenectomy to the relapse, for those who relapsed, and from the splenectomy to the last news for those who didn't relapse. All statistical analyses were performed by $\mathrm{SAS}^{\circledast}$ v 9.1 (SAS Institute Inc., Cary, NC, USA) and Kaplan-Meier curves were designed by GraphPad Prism $^{\circledR}$ v 5.00 for Windows (GraphPad Software, San Diego, California, USA).

*Corresponding author: Nathalie Aladjidi, Pediatric Hematology Unit, Centre de Référence National des Cytopénies Auto-immunes de l'Enfant(CEREVANCE), Hôpital des Enfants, Hôpital Pellegrin, CHU Bordeaux, Place Amélie Raba Léon, 33000 Bordeaux, France, Tel: 00335578202 61; Fax: 00335578202 79; E-mail: nathalie.aladjidi@chu-bordeaux.fr

Received April 20, 2012; Accepted May 16, 2012; Published May 22, 2012

Citation: Aladjidi N, Santiago R, Pondarré C, Lambilliotte A, Leverger G, et al (2012) Revisiting Splenectomy in Childhood Immune Thrombocytopenic Purpura in the Era of New Therapies: The French Experience. J Blood Disorders Transf S3:001. doi:10.4172/2155-9864.S3-003

Copyright: ( 2012 Aladjidi N, et al. This is an open-access article distributed under the terms of the Creative Commons Attribution License, which permits unrestricted use, distribution, and reproduction in any medium, provided the original author and source are credited. 


\section{Results}

\section{Patients' characteristics}

A total of 78 children and adolescents less than 18 years old entered the study. Of 28/30 French hematological pediatric units, 12 had not performed any splenectomy for ITP up to this time, and 16 had performed at least one (median 4, range 2-14). The number of splenectomy performed per year in the country was 5 to 13 . Patient characteristics are presented in Table 1. Two children (3\%), aged 14.7 and 12.5 years, underwent emergency splenectomy for severe bleeding in newly-diagnosed ITP, 14 children (18\%) underwent splenectomy for one or several significant mucous or visceral bleedings and impairing quality of life at a stage of persistent ITP, and 62 children (79\%) underwent splenectomy for one or several significant mucous or visceral bleedings at a stage of chronic ITP. All children had received a median number of 2 (1-7) specific treatments before splenectomy.

\section{Medical and surgical procedures}

The peripheral origin of the thrombocytopenia was confirmed by bone marrow aspiration in 61 children. No secondary etiology was diagnosed in any child at initial diagnosis or during follow-up. An accessory spleen was identified in one case before splenectomy and removed during surgery. Isotopic platelet studies were routinely but not systematically performed in 10 out of 16 units; overall 30/44 children of these units were explored. The results were not available for 2 patients (technical failure due to major thrombocytopenia, missing data). Platelet lifespan was reduced in 28 evaluable cases, with a median value of 2.5 days (0.1-6), confirming the peripheral origin of the thrombocytopenia. Platelet destruction was purely splenic in $71 \%$ $(20 / 28)$, predominantly splenic in $21 \%(6 / 28)$, hepatosplenic in $4 \%$ $(1 / 28)$ and diffuse in $4 \%(1 / 28)$.

Splenectomy was scheduled in $75 / 78$ cases, and performed as an emergency for severe hemorrhage in $3 / 78$ cases (intra-cerebral hemorrhage and massive metrorrhagia in two adolescents with newlydiagnosed ITP, massive hemoperitoneum in a child with chronic ITP lasting for 105 months). The median of average platelet counts in the month before splenectomy was $33 \mathrm{G} / \mathrm{L}$. Immediately before splenectomy, 60/75 children received one or several treatments to raise the platelet count and reduce the per-operative bleeding risk: IVIg alone $(n=32)$, steroids alone $(n=5)$, IVIg plus steroids $(n=11)$, anti-D alone $(n=1)$ or vinblastine alone $(n=1)$, programmed platelets infusions, alone or in association, just before or during surgery

\begin{tabular}{|l|l|l|}
\hline Patients characteristics & Median & Range \\
\hline Sex ratio (M/F) & 0.95 & - \\
\hline Age at diagnosis of ITP (years) & 9.6 & $(0.8-16.5)$ \\
\hline Hemorrhage score (Buchanan) at diagnosis & 2 & $(0-4)$ \\
\hline Platelet count at diagnosis (G/L) & 10 & $(1-99)$ \\
\hline Time from diagnosis to splenectomy (months) & 24.0 & $(1-162)$ \\
\hline Age at splenectomy (years)1 & 12.4 & $(3.5-17.4)$ \\
\hline Number of previous specific treatments ${ }^{2}$ & 2 & $(1-7)$ \\
\hline Hemorrhage score (Buchanan) at splenectomy & 1 & $(0-5)$ \\
\hline Minimal platelet count before splenectomy (G/L) & 4 & $(1-27)$ \\
\hline
\end{tabular}

${ }^{1} 3$ children (4\%) were between 3 and 5 years old at the time of splenectomy ${ }^{2} \mathrm{All}$ the children had received at least one specific platelet-enhancing treatment before splenectomy: first-line treatment: IVIg (median 8 courses, 1 to 96$)(n=75)$ and / or steroids $(n=74)$, second-line treatment $(n=29)$ : rituximab $(n=11)$, anti-D $(n=10)$, hydroxychloroquine $(n=6)$, vinblastine $(n=5)$, cyclosporine $(n=5)$, azathioprine $(n=3)$, mycophenolate mofetil $(n=3)$, dapsone $(n=2)$, eradication of $H$. Pylori $(n=2)$, colchicine $(n=1)$, interferon alpha $(n=2)$.

Table 1: Characteristics of 78 patients before splenectomy for ITP. $(\mathrm{n}=14)$. Laparoscopic splenectomy was performed in $81 \%(62 / 77)$ of children and open splenectomy in 19\% (15/77). Dissection difficulties led ultimately to conversion to open surgery in $18 \%$ of laparoscopic procedures. Accessory spleens were removed in 7 children.

\section{Response to splenectomy}

Outcome for all children: Three patients followed for less than one month after splenectomy were considered as lost to follow-up. For 75 informative children, the median follow-up after splenectomy was 41 months (1-109), inferior to 6 months for 6 of them (Figure 1). The two children who underwent emergency splenectomy, in the context of newly diagnosed ITP with a severe bleeding episode, achieved durable CR within the first days. Overall, CR was achieved at M1 for 79\% (59/75) of children with a median delay to reach CR of 3 days (1-16). Only one child, who was in PR at M1, achieved a later spontaneous CR at 90 days postsplenectomy, and maintained it for all the following period (44 months) without any relapse or treatment. Out of the 59 children who achieved CR at M1, 21 (36\%) experienced a relapse which occurred within the first 7 months in $86 \%$ of cases; no relapse was reported after 50 months (13 informative children). For those 78 children, the 5 -year relapse-free survival was 51\% [IC95\% 37-64] (Figure 2). At the last follow up, $51 \%(38 / 75)$ of the children were in CCR, $84 \%(63 / 75)$ of the children were in CR, and 92\% (69/75) of the children were either in CCR, CR or PR, with an excellent quality of life and minimal unique or intermittent on-demand treatment.

Overall, 28 children out of 75 (37\%) needed a platelet-enhancing treatment after splenectomy: a sole course of IVIg or steroid $(n=11)$, repeated pulses of IVIg and/or steroid $(n=7)$ or a second-line treatment $(n=10)$. Second-line treatments were rituximab $(n=4)$, azathioprine $(\mathrm{n}=3)$, mycophenolate mofetil $(\mathrm{n}=3)$, cyclophosphamide $(\mathrm{n}=2)$, dapsone $(n=2)$, cyclosporine $(n=1)$, hydroxychloroquine $(n=1)$, vinblastine $(n=1)$, androgen $(n=1)$ and thrombopoietin receptor agonists $(n=1)$. At the last follow-up, only five children were still on continuous therapy: azathioprine $(n=3)$, cyclosporine $(n=1)$, thrombopoietin receptor

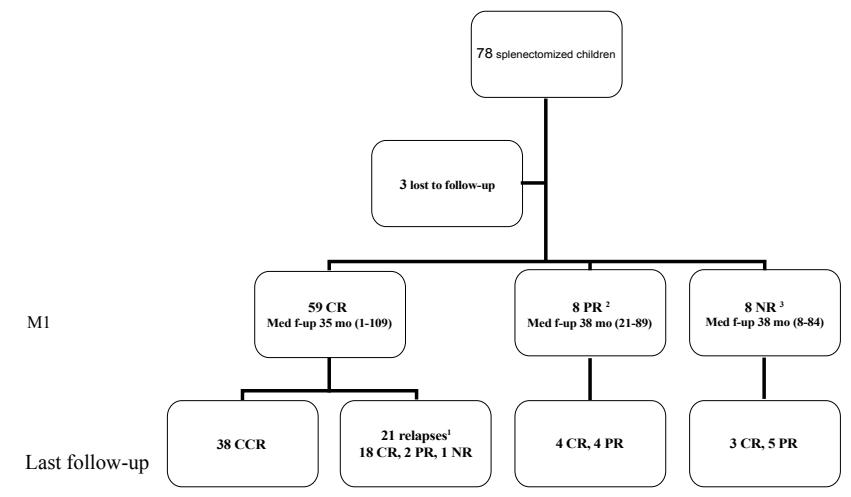

M1: One month post-splenectomy, CCR: Continuous Complete Response, CR Complete Response, PR: Partial Response, NR: No Response. Med F-up: median follow-up.

-For 21 children who experienced a relapse after CR obtention, at the last follow-up, 18 are in CR (4 spontaneously, 12 after pulses of IVIg and / or steroids 2 after 1 to 3 lines), 2 are in PR (spontaneously), and 1 is in NR (after pulses of steroids)

- For 8 children in PR at M1, at the last follow-up, 4 are in CR (1 spontaneously, 2 after pulses of IVIg / steroids, 1 after 1 line), 4 are in PR (2 spontaneously, 2 after pulses of IVIg and / or steroids)

- For 8 children in NR at M1, at the last follow-up, 3 are in CR (3 after 3 to 6 lines, still treated by azathioprine), 5 are in NR ( 1 after pulses of IVIg and / or steroids, 4 after 3 to 8 lines)

Figure 1: Response to splenectomy for 75 children, at one month post-splenectomy and at last followup. 
agonist $(\mathrm{n}=1)$. Among children in PR or NR at the latest news, $6 / 12$ (50\%) experienced further mucous or visceral significant bleeding after splenectomy; a severe intracranial hemorrhage occurred one month after splenectomy in one child with a platelet count at $7 \mathrm{G} / \mathrm{L}$.

Accessory spleen were searched after splenectomy in 8 children in NR by ultrasongraphy $(n=3)$, tomodensitometry $(n=3)$ and/or isotopic studies $(\mathrm{n}=4)$, and found in 5 children. Among those 5 children, 2 were spontaneously or with pulses of IVIg and steroids in CR at the last follow-up, 1 was in PR at the last follow-up without new treatment, and 2 children were in CR after removal of the accessory spleen and thirdline treatment (IVIg plus steroids, and MMF plus steroids).

Outcome for children with chronic ITP: For the subgroup of 59 informative children with chronic ITP, the median follow-up was 38 months (1-109), 83\% (49/59) were in CR at M1. At the last follow-up, $49 \%(29 / 59)$ of the children were in CCR, and $85 \%(50 / 59)$ in CCR or $\mathrm{CR}$ with an excellent quality of life and minimal unique or intermittent ondemand treatment. For those 62 children, the 5-year relapse-free survival was 48\% [IC95\% 32-63] (Figure 2).

Impact of pre-splenectomy isotopic evaluation: $\mathrm{CR}$ was obtained

$\mathbf{A}$

\section{5 year relapse free survival}

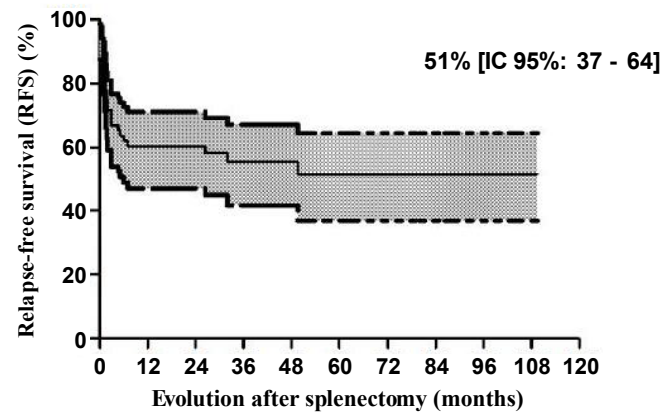

Splenectomised children for ITP: $\mathbf{n}=78$

5 year relapse free survival

B

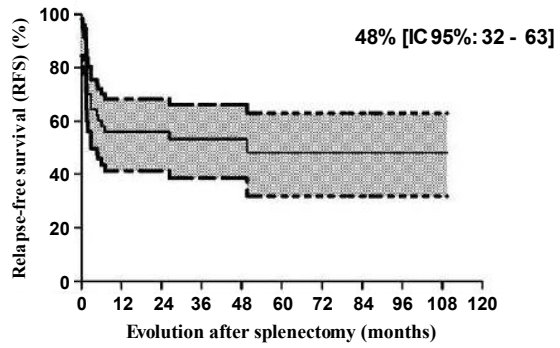

Splenectomised children for chronic ITP: $n=62$

Figure 2: Relapse-free survival after splenectomy for the whole cohort of 78 children (A), and for the subgroup of 62 children with chronic ITP (B) (CI 95\% shown in grey). NB: a relapse was strictly defined by the loss of complete response, even if it was transient, or the need of on-demand or specific treatment. at M1 in 20/26 (77\%) of cases with pure and predominant splenic isotopic destruction, and in none of the two cases of non splenic destruction $(\mathrm{p}=0.11)$. At the last follow-up, in cases of pure and predominant splenic isotopic destruction, CR was maintained in 21/26 (81\%), PR in $2 / 26(8 \%)$ and NR in $3 / 26(11 \%)$; a PR was reached in the 2 cases of non splenic destruction.

Tolerance of the splenectomy: In the postoperative period, $6 \%$ of children required intensive care for immediate surgical complications. 1 severe intra-abdominal hemorrhage requiring open surgery twelve hours after laparoscopy, 1 pleural and peritoneal hemorrhage after laparoscopy, 1 mesenteric and splenic thrombosis after laparotomy with a maximal thrombocytosis of $660 \mathrm{G} / \mathrm{L}$ and no previous thromboprophylaxis, and 1 pulmonary atelectasia after laparoscopy, all four after preparation by at least one platelet-enhancing treatment. Recommended schedules for OPSI prophylaxis were followed in $99 \%$ of children for S. pneumoniae and Haemophilus influenzae immunization, in $63 \%$ of children for N. meningitides immunization, and in $99 \%$ of children for prophylactic antibiotic administration (median duration 3.1 years, $0.4-8.3$ ). The phone contact with the treating physicians at the time of the study, gave the information that no OPSI or deaths due to infection were observed for a 276 person-years observation.

\section{Discussion}

While uncertainties and controversies on splenectomy in childhood ITP have been pointed [20], this study allows us to confirm the value of this procedure in children with ITP. The main interest of our study, when compared to 16 retrospective case series describing approximately 270 children over 50 years, is its national size, highlighting the consistent practices of pediatric hematologists at a country level [21-25]. All the patients at the involved centers responding to inclusion criteria were presented. For 78 children splenectomized in 9 years for primary ITP, the excellent benefit/risk ratio of this rarely used procedure is confirmed. The relatively low value for 5-year relapse-free survival rate is related to the very strict definition of relapse used in this study. This result has to be tempered by the fact that $92 \%$ of long-term survivors are, at the last news, in CCR, CR or PR with minimal treatment and a good quality of life. In this still short 41 months follow-up, overwhelming sepsis was avoided by the wide use of immunization and antibiotic prophylaxis.

Extrapolation from experience in adults is a common practice in pediatrics; however the disease here differs greatly. In children, the course of ITP lasts more than 6 months in only $20-30 \%$ and up to $26 \%$ of them may spontaneously recover between 6 months and 15 years [5]. Unlike previous studies summarized in Table 2, our study included mainly children with primary chronic ITP lasting for more than 12 months and reflects a benefit of splenectomy for $85 \%$ of them, in forms where spontaneous remission is less expected. For adult patients with ITP, splenectomy is the "gold standard" treatment after failure of steroids and IVIg, whereas in children, it is a treatment of last resort, delayed as long as possible. Like many other authors, it is our practice for childhood persistent or chronic ITP to choose the "watch and wait" option for a long time $[6,10]$. Our national data confirms that the practice of splenectomy in children with ITP is rare as the number of new annual chronic ITP could approach 60 to 150 cases, and only 5 to 13 procedures a year were registered. It essentially depends on the habits and beliefs of the referring haematologist. $43 \%$ of French hematology units have not used this treatment in the last 9 years. Children seem to respond to splenectomy slightly better than adults, since it leads to $70-89 \%$ longterm responses, in the main retrospective studies which moreover used 


\begin{tabular}{|c|c|c|c|c|c|c|c|c|}
\hline & $\begin{array}{l}\text { Period, number } \\
\text { of institutions, } \\
\text { number of } \\
\text { patients }\end{array}$ & $\begin{array}{c}\text { Median age at } \\
\text { diagnosis of } \\
\text { ITP }(y)\end{array}$ & $\begin{array}{c}\text { Median age at } \\
\text { splenectomy }(y)^{1}\end{array}$ & $\begin{array}{c}\text { Median delay } \\
\text { diagnosis - sple- } \\
\text { nectomy }(y)^{2}\end{array}$ & $\begin{array}{l}\text { Median follow } \\
\text { up (y) }\end{array}$ & $\begin{array}{l}\text { Global response } \\
\text { at last follow-up }{ }^{4}\end{array}$ & $\begin{array}{l}\text { Peri-operative } \\
\text { bleeding }(n)\end{array}$ & OPSI \\
\hline $\begin{array}{l}\text { El Hafy et al, } \\
2004 \\
\text { Egypte }\end{array}$ & $\begin{array}{l}1980-1996 \\
1 \text { institution } \\
N=112\end{array}$ & NA3 & $9.5(6-16)$ & $0.8(0.3-2.6)$ & $9(5-16)$ & $\begin{array}{l}45 \% \\
>100 \mathrm{G} / \mathrm{L}\end{array}$ & NA & $\begin{array}{l}0 \text { death } \\
2 \text { pneumococ- } \\
\text { cal sepsis } \\
\text { hospitalized } \\
\text { (1 immunization, } \\
2 \text { prophylaxis) }\end{array}$ \\
\hline $\begin{array}{l}\text { Aronis et al, } 2004 \\
\text { Greece }\end{array}$ & $\begin{array}{l}1975-2002 \\
1 \text { institution } \\
N=33\end{array}$ & NA & 12 & $3.3(0.6-14.5)$ & $18.8(6-25)$ & $\begin{array}{l}85 \% \\
>150 \mathrm{G} / \mathrm{L}\end{array}$ & 2 & $\begin{array}{l}1 \text { death, } \\
\text { septic shock } \\
\text { (no immunization, } \\
\text { no prophylaxis) } \\
\text { No sepsis }\end{array}$ \\
\hline $\begin{array}{l}\text { Donato et al, } \\
2006 \\
\text { Italy }\end{array}$ & $\begin{array}{l}1981-2005 \\
1 \text { country, } 7 \\
\text { institutions } \\
\mathrm{N}=30\end{array}$ & 8 & NA & $2.5(1-6)$ & $4.9(1-13)$ & $\begin{array}{l}73 \% \\
>150 \mathrm{G} / \mathrm{L}\end{array}$ & NA & $\begin{array}{l}0 \text { death } \\
\text { Sepsis not speci- } \\
\text { fied }\end{array}$ \\
\hline $\begin{array}{l}\text { Ramenghi et al, } \\
2006 \\
\text { Argentina }\end{array}$ & $\begin{array}{l}\mathrm{NA}-2002 \\
1 \text { country, } 11 \\
\text { institutions } \\
\mathrm{N}=90\end{array}$ & $8(1.3-17.8)$ & $11.3(2.4-22.4)$ & $2.4(0.5-19.4)$ & $3.9(0.4-15)$ & $\begin{array}{l}75 \% \\
>50 \mathrm{G} / \mathrm{L}\end{array}$ & NA & $\begin{array}{l}1 \text { death, sepsis } \\
\text { (immunization } \\
\text { and prophylaxis } \\
\mathrm{NA} \text { ) } \\
10 \text { "infectious } \\
\text { episodes" }\end{array}$ \\
\hline $\begin{array}{l}\text { Kühne et al, } 2007 \\
\text { ICIS }\end{array}$ & $\begin{array}{l}1997-2006 \\
25 \text { countries, } 57 \\
\text { institutions } \\
\mathrm{N}=134\end{array}$ & $9.5(1.1-18.7)$ & $11.8(2.7-20.7)$ & $1.8(0.1-10.8)$ & $2(0.1-4.5)$ & $\begin{array}{l}69 \% \\
>150 \mathrm{G} / \mathrm{L}\end{array}$ & 8 & $\begin{array}{l}0 \text { death } \\
7 \text { sepsis }\end{array}$ \\
\hline $\begin{array}{l}\text { Our study, } 2011 \\
\text { France }\end{array}$ & $\begin{array}{l}2000-2009 \\
1 \text { country, } 16 \\
\text { institutions } \\
\mathrm{N}=78\end{array}$ & $9.6(0.8-16.5)$ & $12.4(3.5-17.4)$ & $2(0.1-13.5)$ & $3.4(0.1-13.5)$ & $\begin{array}{l}84 \% \\
>100 \mathrm{G} / \mathrm{L} \\
51 \% \text { in CCR }\end{array}$ & 2 & $\begin{array}{l}0 \text { death } \\
\text { No sepsis }\end{array}$ \\
\hline
\end{tabular}

${ }^{1}$ Number of children of less than 5 years old: our study: $3 / 78(4 \%){ }^{2}$ Number of children splenectomized for newly-diagnosed or persistent ITP: Kühne: $41 / 134$ (31\%), ou study: 16/78 (20\%), 3NA : Not available. 4NB: response criteria in those studies were heterogeneous.

Table 2: Main informative collaborative studies of children who underwent splenectomy for ITP.

various definitions for response [20]. The standardization of response criteria and response duration is a major issue hindering comparison. Our group aimed to identify a favorable subgroup of patients with the CCR criterion [16]. Like other groups, we have shown that most of the relapses occurred within the first year post splenectomy, and that there were no relapses after 5 years (Figure 2). Adult studies also suggest that the relapse rate may decline with time [15]. Finally, the efficacy of various third-line treatments is to be noticed since $44 \%$ of initial non-responders were in $\mathrm{CR}$ at the time of the latest news. Compared to existing options, at a time when innovative treatments are widely mediatized via the internet for the parents, splenectomy remains in the first place of curative treatments in children.

Our data suggest that in skilled hands, splenectomy is a safe procedure but it is to be noticed that two children, despite the use of adequate previous platelet-enhancing treatments, experienced hemorrhagic complications which is not insignificant. Minimallyinvasive laparoscopy was widely used in $81 \%$ of cases, as currently in most centers [24,26,27]. In our study from 16 different centers, anatomical dissection difficulties however lead to a significant number of conversions to open splenectomy. In symptomatic children, multidisciplinary preventive measures should help to minimize the hemorrhagic risks. The fear of death by OPSI is the major brake for recommending splenectomy in children. After a systematic request, we reported as others a low incidence in children (Table 2). While in older studies, the incidence of OPSI in children was as high as 3.3\% with a mortality rate of $1.7 \%$ [14] it was more recently estimated at 0.23 $0.42 \%$ per year with a lifetime risk of $5 \%$ inversely proportional to age [28]. This risk undoubtedly exists throughout life: in a series of 77 post splenectomy OPSI, the majority occurred 10-30 years after splenectomy [29]. To counterbalance this, a Danish population-based cohort study of 269 splenectomized ITP patients, demonstrated that short and longterm mortality was not increased [30]. In 3812 splenectomized patients for various indications, the overall incidence rates of infections were 7.7 per 100 person-years, to be compared to our 0 per 276 personyears incidence [31]. Close respect of preventive measures should allow to reduce mortality: pre-splenectomy and lifelong immunizations, daily antibiotic prophylaxis, prompt antibiotic treatment of fever, and continuous education of the patient and his entourage [32,33]. Finally, the initial reactive thrombocytosis immediately following a splenectomy is to be monitored and very high trombocytosis may deserve treatment by aspirin. Other potential long term complications of splenectomy in adulthood include thromboembolic events and pulmonary hypertension, but they have not been described in childhood $[34,35]$.

Despite nearly 100 years of experience in splenectomy for ITP, no predictive factor is widely accepted. Study of ${ }^{111}$ Indium-labeled platelet destruction remains the most reliable predictive factor of success; it may also initially help in searching for a differential diagnosis, or in cases of secondary failure of splenectomy, in identifying accessory spleens and guide their further removal [36]. In our study, it was performed in 10 different units distributed in the country and for $68 \%$ of concerned children, when available or when the physician believed in its value. Although the interpretation of our results is clearly limited by the small number of patients, it has to be noted that CR was obtained and maintained in $81 \%$ of cases of splenic platelet destruction, but in none of the cases with non splenic platelet destruction. After the first report in 1997 by Najean of a large series of 268 children and adults 
Citation: Aladjidi N, Santiago R, Pondarré C, Lambilliotte A, Leverger G, et al. (2012) Revisiting Splenectomy in Childhood Immune Thrombocytopenic Purpura in the Era of New Therapies: The French Experience. J Blood Disorders Transf S3:003. doi:10.4172/2155-9864.S3-003

with ITP [37] a recent monocenter British study of 89 splenectomized adults, also showed a $69 \%$ CR rate with pure or predominant splenic destruction versus $20 \%$ of CR with mixed or hepatic destruction [38]. Even if the procedure is long and cumbersome for the patient, it seems useful to recommend it: it is not advisable to propose splenectomy in the event of mixed or hepatic sequestration.

Evidence-based recommendations for splenectomy in pediatric ITP suffer from the lack of authoritative, prospective, comparative studies, which are difficult to set up. Published guidelines tend to be more and more prudent and restrictive regarding splenectomy, in fear of OPSI. The experiences of our group, as others, supports the recommendation to propose splenectomy in older children (preferably over 5 years old), whose ITP has been present for more than 12 months with demonstrable impairment of quality of life including a severe hemorrhage score or thrombocytopenia permanently below $10 \mathrm{G} / \mathrm{L}$ [12]. The search for alternative medical treatment options before proposing splenectomy is a daily concern in the pediatric practice [39]. Besides IVIg and steroids mainly used as first-line treatment in the first year, several second-line treatments may be used. Rituximab, or more recently TPO agonists have been used with success in ITP [40,41]. The place for old and new second line options, to postpone as much as possible the definitive surgical procedure, will be determined when specific comparative pediatric studies have been finalized. Splenectomy could thus be reserved for authentically refractory cases.

In conclusion, this collaborative national study confirms the excellent benefit/risk ratio of splenectomy for childhood primary ITP of prolonged course, although the follow-up is still insufficient. Predictive factors of success remain to be clarified but isotopic evaluation seems to be a good approach to predict it. To be safe, this surgery must be performed by a skilled and concerted multidisciplinary team, for preparation and follow-up. Whatever the treatments proposed, when ITP is cured and the child has become an adult, it is our responsibility to place the referring physician once again in the center of the scene, with a relay of surgeons and hematologists, for lifelong survey of infectious and thrombotic risk.

\section{Acknowledgement}

The authors would like to thank patients and families, and all CEREVANCE physicians and surgeons for their participation, and Magali Huger, Florence Viard and Helder Fernandes for data collection and phone contacts.

\section{References}

1. Terrell DR, Beebe LA, Vesely SK, Neas BR, Segal JB, et al. (2010) The incidence of immune thrombocytopenic purpura in children and adults: A critical review of published reports. Am J Hematol 85: 174-180.

2. Barnard D, Woloski M, Feeny D, McCusker P, Wu J, et al. (2003) Development of disease-specific health-related quality-of-life instruments for children with immune thrombocytopenic purpura and their parents. J Pediatr Hematol Oncol 25: 56-62.

3. Blanchette V, Bolton-Maggs P (2010) Childhood immune thrombocytopenic purpura: diagnosis and management. Hematol Oncol Clin North Am 24: 249273.

4. Buchanan GR, Adix L (2006) Current challenges in the management of children with idiopathic thrombocytopenic purpura. Pediatr Blood Cancer 47: 681-684.

5. Imbach P, Kühne T, Müller D, Berchtold W, Zimmerman S, et al. (2006) Childhood ITP: 12 months follow-up data from the prospective registry I of the Intercontinental Childhood ITP Study Group (ICIS). Pediatr Blood Cancer. 46: 351-356.

6. Kühne T (2003) Investigation and management of newly diagnosed childhood idiopathic thrombocytopenic purpura: problems and proposed solutions. J Pediatr Hematol Oncol 25: S24-S27.
7. Psaila B, Petrovic A, Page LK, Menell J, Schonholz M, et al. (2009) Intracranial hemorrhage (ICH) in children with immune thrombocytopenia (ITP): study of 40 cases. Blood 114: 4777-4783.

8. Chanock S (2003) The etiology of childhood immune thrombocytopenic purpura: how complex is it? J Pediatr Hematol Oncol 25: S7-S10.

9. Cines DB, Bussel JB, Liebman HA, Luning Prak ET (2009) The ITP syndrome: pathogenic and clinical diversity. Blood 113: 6511-6521

10. Stasi R, Evangelista ML, Stipa E, Buccisano F, Venditti A, et al. (2008) Idiopathic thrombocytopenic purpura: current concepts in pathophysiology and management. Thromb Haemost 99: 4-13.

11. British Committee for Standards in Haematology General Haematology Task Force (2003) Guidelines for the investigation and management of idiopathic thrombocytopenic purpura in adults, children and in pregnancy. $\mathrm{Br} \mathrm{J}$ Haemato 120: $574-596$.

12. George JN, Woolf SH, Raskob GE, Wasser JS, Aledort LM, et al. (1996 Idiopathic thrombocytopenic purpura: a practice guideline developed by explicit methods for the American Society of Hematology. Blood 88: 3-40.

13. Neunert C, Lim W, Crowther M, Cohen A, Solberg L Jr, et al. (2011) The American Society of Hematology 2011 evidence-based practice guidelinfe for immune thrombocytopenia. Blood 117: 4190-4207

14. Provan D, Stasi R, Newland AC, Blanchette VS, Bolton-Maggs P, et al. (2010) International consensus report on the investigation and management of primary immune thrombocytopenia. Blood 115: 168-186.

15. Godeau B, Provan D, Bussel J (2007) Immune thrombocytopenic purpura in adults. Curr Opin Hematol 14: 535-556.

16. Aladjidi N, Leverger G, Leblanc T, Picat MQ, Michel G, et al. (2011) New insights into childhood autoimmune hemolytic anemia: a French national observational study of 265 children. Haematologica 96: 655-663.

17. Rodeghiero F, Stasi R, Gernsheimer T, Michel M, Provan D, et al. (2009) Standardization of terminology, definitions and outcome criteria in immune thrombocytopenic purpura of adults and children: report from an international working group. Blood 113: 2386-2393.

18. (1988) Recommended method for indium-111 platelet survival studies. International Committee for Standardization in Hematology. Panel on Diagnostic Applications of Radionuclides. J Nucl Med 29: 564-566.

19. Buchanan GR, Adix L (2002) Grading of hemorrhage in children with idiopathic thrombocytopenic purpura. J Pediatr 141: 683-688.

20. Minkov M (2006) Critical issues concerning splenectomy for chronic idiopathic thrombocytopenic purpura in childhood. Pediatr Blood Cancer 47: 734-736.

21. Aronis S, Platokouki H, Avgeri M, Pergantou H, Keramidas D (2004) Retrospective evaluation of long-term efficacy and safety of splenectomy in chronic idiopathic thrombocytopenic purpura in children. Acta Paediatr 93: 638642

22. Donato H, Picón A, Rapetti MC, Rosso A, Schvartzman G, et al. (2006) Splenectomy and spontaneous remission in children with chronic idiopathic thrombocytopenic purpura. Pediatr Blood Cancer 47: 737-739.

23. El-Alfy MS, El-Tawil MM, Shahein N (2003) 5- to 16-year follow-up following splenectomy in chronic immune thrombocytopenic purpura in children. Acta Haematol 110: 20-24.

24. Kühne $T$, Blanchette $V$, Buchanan $G R$, Ramenghi $U$, Donato $H$, et al (2007) Splenectomy in children with idiopathic thrombocytopenic purpura: A prospective study of 134 children from the Intercontinental Childhood ITP Study Group. Pediatr Blood Cancer 49: 829-834.

25. Ramenghi U, Amendola G, Farinasso L, Giordano P, Loffredo G, et al. (2006 Splenectomy in children with chronic ITP: long-term efficacy and relation between its outcome and responses to previous treatments. Pediatr Blood Cancer 47: 742-745

26. Dolan JP, Sheppard BC, DeLoughery TG (2008) Splenectomy for immune thrombocytopenic purpura: surgery for the 21st century. Am J Hematol 83: 93 96.

27. Rescorla FJ, West KW, Engum SA, Grosfeld JL (2007) Laparoscopic splenic procedures in children: experience in 231 children. Ann Surg 246: 683-687.

28. Bisharat N, Omari H, Lavi I, Raz R (2001) Risk of infection and death among post-splenectomy patients. J Infect 43: 182-186. 
Citation: Aladjidi N, Santiago R, Pondarré C, Lambilliotte A, Leverger G, et al. (2012) Revisiting Splenectomy in Childhood Immune Thrombocytopenic Purpura in the Era of New Therapies: The French Experience. J Blood Disorders Transf S3:003. doi:10.4172/2155-9864.S3-003

29. Scheiermann P, Rösch I, Nerlich AG, Huf R, Kunz SN, et al. (2011) Unusual presentation of Streptococcus pneumoniae-induced septic shock 36 years after splenectomy. Infection 39: 283-285.

30. Yong M, Thomsen RW, Schoonen WM, Farkas DK, Riis A, et al. (2010) Mortality risk in splenectomised patients: a Danish population-based cohort study. Eur $\mathrm{J}$ Intern Med 21: 12-16.

31. Thomsen RW, Schoonen WM, Farkas DK, Riis A, Jacobsen J, et al. (2009) Risk for hospital contact with infection in patients with splenectomy: a populationbased cohort study. Ann Intern Med 151: 546-555.

32. Newland A, Provan D, Myint S (2005) Preventing severe infection after splenectomy. BMJ 331: 417-418.

33. Price VE, Dutta S, Blanchette VS, Butchart S, Kirby M, et al. (2006) The prevention and treatment of bacterial infections in children with asplenia or hyposplenia: practice considerations at the Hospital for Sick Children, Toronto. Pediatr Blood Cancer 46: 597-603.

34. Sarpatwari A, Bennett D, Logie JW, Shukla A, Beach KJ, et al. (2010) Thromboembolic events among adult patients with primary immune thrombocytopenia in the United Kingdom General Practice Research Database. Haematologica 95: 1167-1175.

35. Thomsen RW, Schoonen WM, Farkas DK, Riis A, Fryzek JP, et al. (2010) Risk of venous thromboembolism in splenectomized patients compared with the general population and appendectomized patients: a 10-year nationwide cohort study. J Thromb Haemost. 8: 1413-1416.

36. Bader-Meunier B, Proulle V, Trichet C, Debray D, Gabolde M, et al. (2003) Misdiagnosis of chronic thrombocytopenia in childhood. J Pediatr Hemato Oncol 25: 548-552.

37. Najean Y, Rain JD, Billotey C (1997) The site of destruction of autologous 111 In-labelled platelets and the efficiency of splenectomy in children and adults with idiopathic thrombocytopenic purpura: a study of 578 patients with 268 splenectomies. Br J Haematol 97: 547-550.

38. Sarpatwari A, Provan D, Erqou S, Sobnack R, David Tai FW, et al. (2010) Autologous 111 Inlabelled platelet sequestration studies in patients with primary immune thrombocytopenia (ITP) prior to splenectomy: a report from the United Kingdom ITP Registry. Br J Haematol 151: 477-487.

39. Stasi R, Newland A, Thornton P, Pabinger I (2010) Should medical treatment options be exhausted before splenectomy is performed in adult ITP patients? A debate. Ann Hematol 89: 1185-1195.

40. Bussel JB, Buchanan GR, Nugent DJ, Gnarra DJ, Bomgaars LR, et al. (2011) A randomized, double-blind study of romiplostim to determine its safety and efficacy in children with immune thrombocytopenia. Blood 118: 28-36.

41. Ducassou S, Aladjidi N, Lutz P (2010) Rituximab in the management of chronic immune thrombocytopenic purpura: what is its place? Pediatr Blood Cancer 54: 632 